\title{
Trichomycete Fungi (Zygomycota) Associated with the Digestive Tract of Simulium goeldii Cerqueira \& Nunes de Mello and Simulium ulyssesi (Py-Daniel \& Coscarón) (Diptera: Simuliidae) Larvae, in Central Amazônia, Brazil
}

\author{
Claudia Ríos-Velásquez, Neusa Hamada*/+
}

\begin{abstract}
Laboratório de Biodiversidade, Centro de Pesquisas Leônidas e Maria Deane, Instituto Oswaldo Cruz-Fiocruz, Manaus, AM, Brasil *Coordenação de Pesquisas em Entomologia, Instituto Nacional de Pesquisas da Amazônia, Caixa Postal 478, 69011-970 Manaus, AM, Brasil
\end{abstract}

Trichomycete fungi are associated with digestive tract of black fly larvae. These fungi have not been studied in Brazil, knowing them and their relationship with black flies could be an alternative to control vector populations. The objectives of this study were to survey the Trichomycete fungi associated with larvae of Simulium goeldii and $\mathrm{S}$. ulyssesi, and to determine if there is specificity and/or difference in the infection rates in these species. Black flies were collected in Central Amazônia, Brazil. Three genera of Trichomycetes were found: Harpella, Genistellospora and Smittium. All these fungi were common to both black fly species.

Key words: black fly - Trichomycetes - Amazon

The Trichomycetes are filamentous fungi that live in the digestive tract of arthropods, including a great variety of insect families (Labeyrie et al. 1996, Lichtwardt 1997, Misra 1998, Lichtwardt et al.1999). Arthropods are infected by Trichomycetes after ingestion of trichospores or zygospores (in the order Harpellales). These spores attach themselves by a holdfast ("foot") to the peritrophic matrix in the midgut and to the chitinous intima in the hindgut without penetrating the walls of the intestine; in this way, no physical injury is caused to the wall of the intestine (Lichtwardt 1986).

Black fly larvae have been reported as hosts of a large number of Trichomycetes species in the genera Paramoebidium, Harpella, Genistellospora, Graminelloides, Pennella, Simuliomyces, Smittium and Stipella (Moss \& Lichtwardt 1980, Lichtwardt 1997, Misra 1998). However, fungal host specificity is not widely studied; it can vary among taxa but is, in general, restricted at the genus or family level (Lichtwardt 1986). In some cases trichomycetes show species specificity (Lichtwardt \& Williams 1988, Lichtwardt 1997) such as Smittium dimorphum Lichtwardt \& Williams and Stachylina pedifer Williams \& Lichtwardt that have only been reported in Boreoheptagyia lurida (Garret) (Chironomidae) larvae (Lichtwardt \& Williams 1988).

This study received partial financial support from the Third World Academy of Sciences (TWAS), CNPq (grant \# 400028/ 99-9), PPI 1-3400 and PPI 1-3070 (MCT/INPA). The senior author received an MSc fellowship from CapesS-PEC/PG-Inpa. ${ }^{+}$Corresponding author. Fax: +55-92-642.8909. E-mail: nhamada@inpa.gov.br

Received 5 April 2001

Accepted 19 February 2002
In general, the Trichomycetes are commensalistic, but the type of relationship with the host can vary according developmental characteristics of the host and environmental parameters of the host's habitat. Species in the order Harpellales have a mutualistic relationship with their host, but some species have been reported as parasites of black fly ovaries (e.g Yeboah et al. 1984, Labeyrie et al. 1996, Lichtwardt 1996) or as pathogenic to the larval host (Sweeney 1981, Grigg \& Williams 1989, López Lastra 1990, Garcia et al. 1994, Lichtwardt 1996).

Studies on Trichomycetes in aquatic environments in South America are restricted to Chile and Argentina (López Lastra 1990, Lichtwardt \& Arenas 1996, Lichtwardt et al. 1999, 2000); in Brazil there is no report of an association between these fungi and black flies. If trichomycetes are species specific it could be possible to distinguish host species that are morfologically similar, such as Simulium goeldii Cerqueira \& Nunes de Mello and S. ulyssesi (PyDaniel \& Coscarón), based on the presence of Trichomycetes species. These two black fly species can be distinguished at the larval stage only in the last instar, after dissecting the gill histoblast and counting the number of gill filaments (Hamada \& Adler 2001).

Knowledge of Trichomycete fungi and their relationship with black flies might be a valuable tool in biological control of vector populations. This study will help to increase this knowledge in Central Amazônia by (1) surveying the Trichomycetes (Zygomycota) associated with the digestive tract of $S$. goeldii and S. ulyssesi larvae; (2) determining the frequency of Trichomycetes in the two black fly host species and (3) determining if there is any difference in the occurrence of genera of trichomycetes between these two black fly host species.

Black fly larvae were collected monthly from April to October 1999 in streams in Presidente Figueiredo and 
Manaus (Reserva Florestal Adolfo Ducke) counties, Amazonas, Brazil. In these places, $S$. goeldii and $S$. ulyssesi are present throughout the year.

The larvae were hand collected, placed in Petri dishes with wet filter paper and transported to the laboratory in an ice box. In the laboratory the larvae were transferred to a refrigerator until dissection. Due to the great morphological similarity between the two black fly species studied, last-instar larvae were identified by dissecting the gill histoblast in distilled water. S. goeldii has eight filaments and S. ulyssesi has six (Hamada \& Adler 2001). Larvae in the penultimate instar were classified as immature because their gill histoblast is not developed; therefore, it was not possible to identify them to species level.

Dissections of the mid- and hindgut were done in distilled water. These structures were mounted between slide and coverslip in distilled water and examined under a compound microscope to observe presence or absence of the Trichomycetes. Measurements of thalli and spores were made before staining; identification was based on Lichtwardt's (1986) key to Trichomycetes. The fungi were stained with blue lactophenol, and, after complete substitution of water by the stain, the coverslip was sealed with transparent fingernail polish.

Infection rates of fungi in the black fly host species were defined as the number of infected larvae divided by the total number of larvae examined of each species (Lichtwardt 1986). To verify if there are differences in the infection rates by Trichomycetes in $S$. goeldii and $S$. ulyssesi and between last instar and penultimate instar larvae, a chi-square test $(\alpha=0.05)$ was performed.

Dissections were performed on 202 larvae, of which 68 were S. goeldii, 55 were $S$. ulyssesi and 79 were immature. Three genera of trichomycetes were observed: Harpella, Smittium and Genistellospora. Identifying to species level was not possible because of the difficulty in observing the structures that characterize each species and, in some cases, because the measurements of the structures did not match those of known trichomycetes species. It is possible that many of these structures were not mature and/or that they belong to species that have not yet been described. However, based on the structures observed, there is probably only one species of each genus: Harpella sp. (Fig. 1), Smittium sp. (Figs 2-3) and Genistellospora sp. (Figs 4-5).

Of the total dissected larvae, $9.4 \%$ were not infected with Trichomycetes (Table). Harpella sp. was only observed in the midgut of both black fly species, including the immature larvae, with similar infection rates (Table); specificity to any of the two species was not observed.

Genistellospora sp. and Smittium sp. were observed infecting only the hindgut of $S$. goeldii and S. ulyssesi, and the immature larvae. Infection rates of Genistellospora sp. (Table) were not significantly different in the two black fly species studied $\left(\chi^{2}, \mathrm{p}>0.05\right)$, while Smittium sp. had higher infection rates in $S$. goeldii than in $S$. ulyssesi (Table) $\left(\chi^{2}, \mathrm{p}<0.05\right)$.

The rates of infection by trichomycetes in the hindgut were lower $\left(\chi^{2}, \mathrm{p}<0.05\right)$ in penultimate-instar (immature) than in last-instar S. goeldii and S. ulyssesi larvae (Table).
Some specimens of black flies were infected in the hindgut with the two Trichomycetes species observed, double infection being more frequently $\left(\chi^{2}, \mathrm{p}<0.05\right)$ found in $S$. goeldii than in S. ulyssesi (Table).

The genus Harpella is cosmopolitan and, in general, its host specificity is not at the specific level. The results of the present study support this hypothesis because Harpella sp. was found in both black fly species studied. The observed structures, holdfast (Fig. 1) and trichospores attached to the thallus, indicate the presence of only one species, similar to H. meridianalis, however, Harpella sp., has thallus and trichospores shorter and thinner than those of H. meridianalis (Lichtwardt \& Arenas 1996, Lichtwardt et al. 1999, 2000).

Our results also show that Genistellospora sp. and Smittium sp. do not have specificity for the black fly species studied. Specificity of Trichomycetes for their host species has not been well studied; and only has been inferred from data obtained in the field (Lichtwardt 1986). Probably it is related to environmental and behavioral factors, which may determine if the fungus becomes established in a given population (Lichtwardt 1986).

Smittium sp. (Figs 2-3) is similar to species reported in black fly larvae in Costa Rica (Lichtwardt 1997): Smittium annulatum Lichtwardt and Smittium dipterorum Lichtwardt, but probably it is a new species. Smittium sp. has trichospore oval-elongated like that of S. annulatum, however the trichospore is shorter and thinner; it is more similar to $S$. dipterorum, having thallus with verticilated ramification, holdfast with horse-shoe shape, trichospore

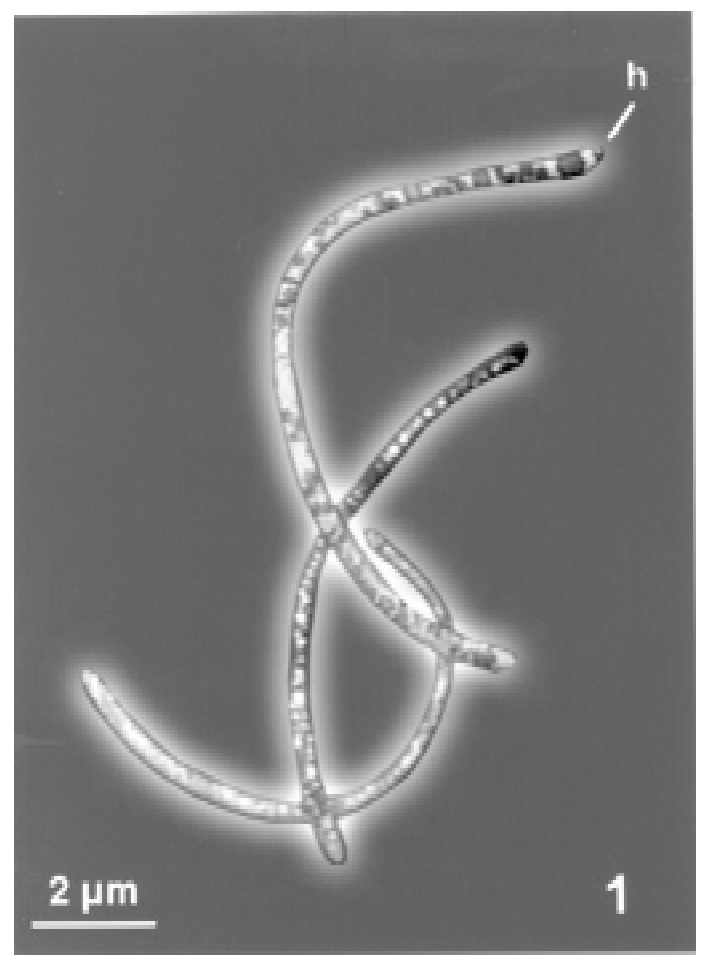

Fig. 1: Harpella sp. (Zygomycota: Trichomycetes) from midgut of Simuliidae (Diptera) larvae in Central Amazônia, Brazil. Thallus and holdfast (h) 
TABLE

Infection rates (\%) of Trichomycetes (Zygomycota) in Simulium goeldii, Simulium ulyssesi and immature (penultimate instar) larvae (Diptera: Simuliidae) observed from April to October 1999 in Central Amazônia, Brazil

\begin{tabular}{|c|c|c|c|c|c|}
\hline \multirow[t]{2}{*}{ Simuliidae } & \multicolumn{4}{|c|}{ Infected with Trichomycetes (\%) } & \multirow{2}{*}{$\begin{array}{c}\text { Non infected } \\
\text { larvae }(\%)\end{array}$} \\
\hline & Harpella & Smittium & Genistellospora & Genistellospora/Smittium & \\
\hline $\begin{array}{l}\text { S. goeldii } \\
\mathrm{n}=68\end{array}$ & 89.7 & 39.7 & 44.1 & 19.1 & 5.8 \\
\hline $\begin{array}{l}\mathrm{n}=55 \\
\text { Immatures }\end{array}$ & 89.1 & 18.2 & 34.5 & 1.8 & 7.2 \\
\hline $\mathrm{n}=79$ & 73.4 & 25.3 & 17.7 & 6.3 & 15.2 \\
\hline
\end{tabular}

$\mathrm{n}$ : total number of specimens examined; Genistellospora/Smittium: double infection
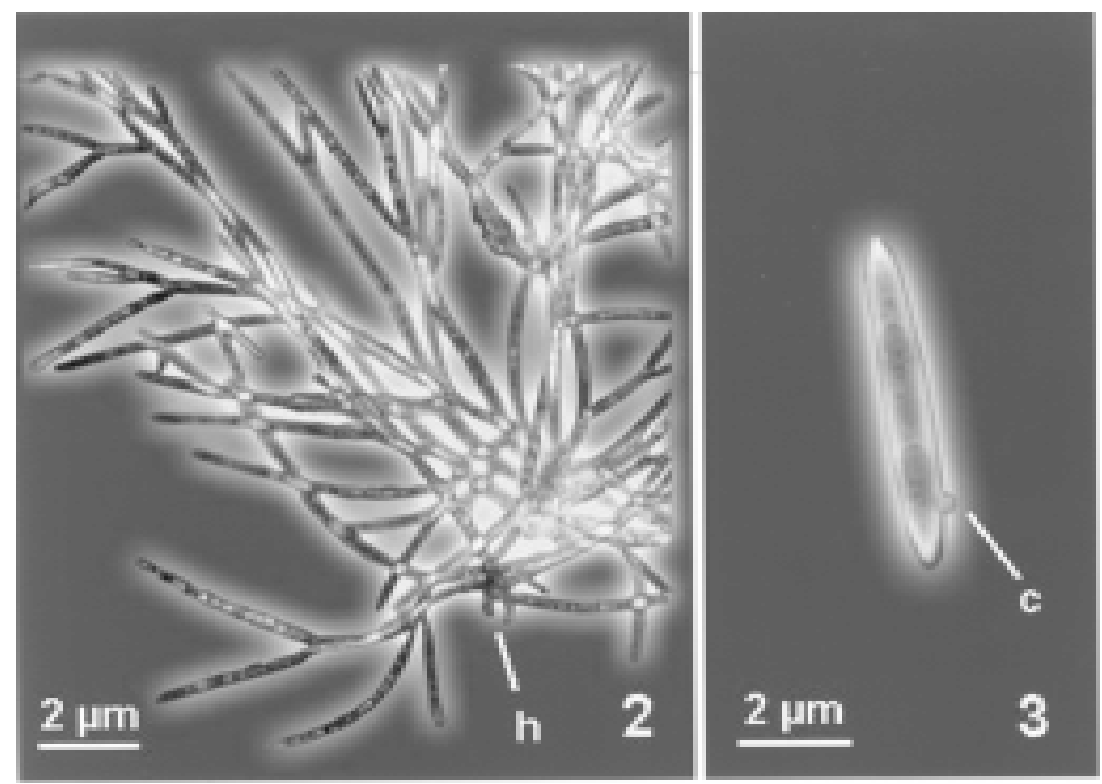

Fig. 2: Smittium sp. (Zygomycota: Trichomycetes) from hindgut of Simuliidae (Diptera) larvae, in Central Amazônia, Brazil. Thallus ramification and bifid holdfast (h). Fig. 3: trichospore with collar (c)

elongated, almost cylindrical with one appendix and a short collar; however, the sizes of the trichospore and thallus differ from those of $S$. dipterorum. Genistellospora sp. (Figs 4-5) has structures similar to those of Genistellospora homothallica Lichtwardt, reported by Lichtwardt (1997) in Chile, Costa Rica and Argentina, however, the length and width of its zygospore are much smaller.

Genistellospora sp. and Smittium sp. were found coocurring in the host species. It is possible to find one species of Trichomycetes infesting many species of hosts, but also one species of host may be infected by two or more Trichomycetes (Lichtwardt 1986).

Infection rates of Trichomycetes in black fly larvae have not been reported previously. Probably infection rate is affected by the host species and by environmental conditions (Lichtwardt 1986). In the present study we report only the infection rates of black fly species; we did not consider the habitat conditions because of the similarity of the habitats and because of the low number of larvae in some places.
Infection rates were lower in immature larvae than in last-instar larvae. This result is the opposite of that of Horn and Lichtwardt (1981), who observed that, under laboratory conditions, infection rates in larvae decreased from the first to the fourth-instar in Aedes aegypti and that the rate of re-infection decreased in each molting period. In the present study we did not observe firstinstar larvae, we worked only with penultimate and ultimate instars. We expected that larvae would become reinfected after each ecdysis, since, during this process, the hindgut and its chitinous sheath also change, and the exuviae can have viable fungi for re-infection of surrounding larvae. One possible explanation of the higher infection rates in the last-instar is that the larvae in this stage are preparing to pupate and would need larger amounts of vitamins, and that the associated fungi in the hindgut could help in the absorption or production of these vitamins. Therefore, last instar larvae could be more receptive (through biochemical or physiological mechanisms) to infection by Trichomycetes in the hindgut than the immature larvae. Horn and Lichtwardt (1981) observed 

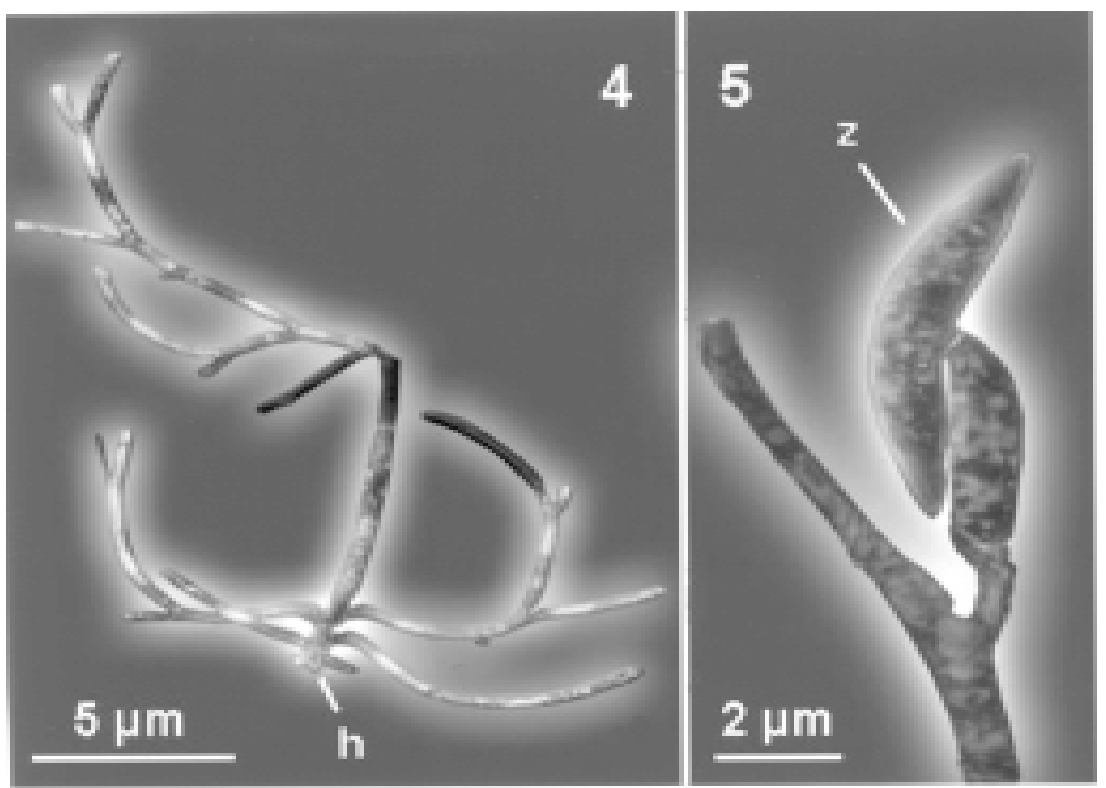

Genistellospora sp. (Zygomycota: Trichomycetes) from hindgut of Simuliidae (Diptera) larvae, in Central Amazônia, Brazil. Fig. 4: thallus ramification and holdfast (h). Fig. 5: zygospore (z)

that, under laboratory conditions, A. aegypti larvae are not infected by fungi in media rich in vitamins. It is possible that fungal infection is determined by the physiological condition of the larvae. More studies will be necessary to clarify the infection process and the factors associated with it.

This is the first report of Trichomycetes fungi associated with aquatic insects in Brazil. Because of the economic importance of controlling some aquatic insects, many of which are disease vectors or biting pests, these fungi could potentially be used economically since some species can be pathogenic to their host.

\section{ACKNOWLEDGMENTS}

To João Bosco Lapa, Luis Aquino, Fernando Gouvea, David Santana, Assunção de Oliveira and Teiamar Bobot for field assistance. Robert Lichtwardt helped with the identification of Trichomycetes and, together with Philip M Fearnside, made helpful comments on the manuscript.

\section{REFERENCES}

Garcia JJ, Campos RE, Maciá A 1994. Prospección de enemigos naturales de Culicidae (Diptera) de la selva marginal de Punta Lara (Prov. De Buenos Aires, República Argentina), Rev Acad Colombiana Ciencias Exactas Nat 19: 209-215.

Grigg RD, Williams MC 1989. Distribution of Amoebidium and Smittium species (Trichomycetes) in mosquito larvae on the Platte river floodplain of Central Nebraska. Trans $\mathrm{Ne}$ braska Acad Sci 17: 23-28.

Hamada N, Adler PH 2001. Bionomia e chave para espécies de Simulium (Diptera: Simuliidae) na Amazônia Central, Brasil. Acta Amazonica 31: 109-132.

Horn BW, Lichtwardt RW 1981. Studies on the nutritional relationship of larval Aedes aegypti (Diptera: Culicidae) with Smittium culisetae (Trichomycetes). Mycologia 73: 724-740.

Labeyrie ES, Molloy DP, Lichtwardt R 1996. An investigation of Harpellales (Trichomycetes) in New York State Blackflies (Diptera: Simuliidae). J Inv Path 68: 293-298.
Lichtwardt RW 1986. The Trichomycetes: Fungal Associates of Arthropods, Springer-Verlag, New York, 343 pp.

Lichtwardt RW 1996. Trichomycetes and the arthropod gut. In D Howard, D Miller (eds), The Mycota, Animal and Human Relations, Springer-Verlag, Berlin, p. 314-330.

Lichtwardt RW 1997. Costa Rican gut fungi (Trichomycetes) infecting lotic insect larvae. Rev Biol Trop 45: 1349-1383.

Lichtwardt RW, Arenas MJ 1996. Trichomycetes in aquatic insects from southern Chile. Mycologia 88: 844-857.

Lichtwardt RW, Williams MC 1988. Distribution and species diversity of Trichomycetes gut fungi in aquatic insect larvae in two Rocky Mountain streams. Can J Bot 66: 12591263.

Lichtwardt RW, Ferrington Jr LC, López Lastra C 1999. Trichomycetes in Argentinean aquatic insect larvae. Mycologia 91: 1060-1082.

Lichtwardt RW, López Lastra C, Mazzucchelli MG 2000. Fungi living in the guts of larval aquatic insects in northwestern Argentina. Mycologia 92: 332-340.

Lichtwardt RW, White MM, Cafaro MJ 1999. Fungi associated with passalid beetles and their mites. Mycologia 91: 604702.

López Lastra C 1990. Primera cita de Smittium morbosum var. rioplatensis var. nov. (Trichomycetes: Harpellales) patógeno de cinco especies de mosquitos (Diptera: Culicidae) en la República de Argentina. Re Arg Mic 13: 14-18.

Misra JK 1998. Trichomycetes fungi associated with arthropods: Review and world literature. Symbiosis 24: 179220.

Moss ST, Lichtwardt RW 1980. Harpella leptosa, a new species of Trichomycetes substantiated by electron microscopy. Can J Bot 58: 1035-44.

Sweeney AW 1981. Fungal pathogens of mosquito larvae. Chapter 14. In EW Davidson, Pathogenesis of Invertebrate Microbial Disease, Manheld, Osmun, Tetowa, NJ, USA, p. 403-423.

Yeboah DO, Undeen AH, Colbo MH 1984. Phycomycetes parasitizing the ovaries of blackflies (Simuliidae). J Inver Path 43: 363-373. 